\title{
Artigos
}

Marcella Oliveira Araujo' Ana Paula Soares da Silva²

\section{O cuidado de bebês de 0 a 3 anos em uma comunidade de assentados da reforma agrária ${ }^{3}$}

Resumo: A partir de uma abordagem que considera a constituição relacional e situada dos sujeitos em desenvolvimento, este artigo tem por objetivo apresentar um retrato do cuidado de bebês de 0 a 3 anos em comunidade, obtido a partir de uma pesquisa de mestrado, que estudou o cotidiano de um grupo de crianças e famílias no contexto de assentamento da reforma agrária. A organização dos tempos e dos ambientes de cada criança, pelas pessoas do seu universo relacional, revelou uma prática comunitária do cuidado, na qual suas necessidades e vontades são inseridas como parte das atividades coletivas de cada família. Verificamos que o modo de vida no campo é perpassado por uma forte rede de solidariedade, para o cuidado da criança pequena, criada entre os membros de diferentes gerações da família.

Palavras-chave: Bebês; Cuidado; Família; Comunidade; Reforma Agrária.

\section{Caring for babies from 0 to 3 years of age in a community of land reform settlers}

Abstract: Based on an approach that considers the relational and situated constitution of the subjects in development, this article aims to present a picture about the care of infants from 0 to 3 years in community. This study was obtained from a master's research about the daily life of a group of children and families in the context of settlement of the land reform. The organization of the times and environments of each child, by the people of their relational universe, revealed a community practice of care, in which their needs and wants are inserted as part of the collective activities of each family. We find that the way of life in the countryside is permeated by a strong network of solidarity to care for babies, created among the members of different generations of the family.

Keywords: Babies; Care; Family; Community; Land Reform.

\footnotetext{
'Psicóloga e pesquisadora do Laboratório de Psicologia Socioambiental e Práticas Educativas - LAPSAPE, Faculdade de Filosofia, Ciências e Letras de Ribeirão Preto - USP. E-mail: marce.o.araujo@gmail.com

${ }^{2}$ Doutora em Psicologia pela Universidade de São Paulo. Realizou estágio doutoral na Katholieke Universiteit Nijmegen (Holanda). É Pós-doutora pelo Instituto de Psicologia da Universidade de São Paulo, Departamento de Psicologia Social e do Trabalho (IPUSP). Professora do Departamento de Psicologia da Faculdade de Filosofia, Ciências e Letras de Ribeirão Preto - Universidade de São Paulo (FFCLRP-USP); Coordenadora do Laboratório de Psicologia Socioambiental e Práticas Educativas (LAPSAPE/FFCLRP-USP).

E-mail: apsoares.silva@usp.br

3 Pesquisa financiada pela Fundação de Amparo à Pesquisa do Estado de São Paulo (FAPESP - Processo n.2011/04040-1) e pela

Coordenação de Aperfeiçoamento de Pessoal de Nível Superior - CAPES, Programa de Demanda Social.
} 


\section{Introdução}

s discussões sobre o cuidado das crianças pequenas, na Psicologia do Desenvolvimento,
refletem uma variedade de abordagens atreladas basicamente à história de constituição da área,
que caminhou da investigação de aspectos individuais à consideração da constituição relacional e situada dos sujeitos em desenvolvimento (ROSSETTII-FERREIRA, 2006). Na atualidade, embora convivam diferentes abordagens, são comuns aquelas que colocam a centralidade no desenvolvimento em contexto e se interessam em como as pessoas se constituem como membros de comunidades culturais. Para Fidalgo (2004), os estudos do desenvolvimento humano, nessas perspectivas, passaram a enfatizar, simultaneamente, a individualidade (uniqueness) e o relacionamento (relatedness) da pessoa com as unidades sociais. Neste sentido, buscaram ultrapassar a parcialidade de modelos que mantinham a dicotomia e a dualidade entre indivíduo e sociedade.

Deriva desta concepção o reconhecimento de que não há "sujeito", "criança”, "infância", "família", "ambiente" em termos genéricos e que, para compreendermos os processos vividos pelas crianças, é necessário investigar seus modos de participação em seus grupos culturais (ROGOFF, 2005). Assim, conhecer o conjunto de personagens e cenários das vidas das crianças pequenas torna-se um aspecto central para o entendimento dos processos de desenvolvimento psicológico (ROGOFF, 1998).

As contribuições de Vigotski (2006), para esses desdobramentos, foram cruciais, uma vez que o autor inspira uma concepção de sujeito que se constrói na relação com o outro e com o mundo, ou seja, sócio historicamente constituído nas múltiplas e significativas vivências com sujeitos mais experientes na cultura de um grupo determinado. Para o autor, as relações da criança estão imbricadas ao ambiente, de modo que:

a comunicação com o adulto é a esfera fundamental onde se revela a própria atividade da criança, pois quase toda a atividade pessoal do bebê se integra em suas relações sociais. A atitude dos bebês ante o mundo exterior se revela sempre através de outras pessoas. Portanto, a conduta individual do bebê está imersa, entrelaçada com o social, e todas as manifestações sociais do bebê estão dentro da situação concreta, formando com ela um todo único e indivisível (VIGOSTKI, 2006, p. 303).

Este todo indivisível foi muito bem tratado na obra de Wallon (1986), que concebeu o bebê por inteiro, em relação de interdependência com outro. Para o autor, sendo um ser biologicamente social, o bebê humano necessita do outro para sobreviver. O nascimento do bebê, como uma separação física da mãe, constitui-se dessa forma parte do processo de (des)continuidade da ligação biológica e afetiva entre eles.

Desde um referencial vigotskiano, Pino (2005) defende que o diferencial do ser humano estaria na cultura, através da qual o social adquire sempre novas formas de existência. Estas formas de existência apresentam-se por meio de uma sociabilidade perpassada por diferentes modos de organização das 
relações. O bebê, suas necessidades e relações encontram-se intimamente entrelaçados, de modo que questões biológicas adquirem significados que, cotidianamente, são atribuídos pelos outros com quem interage.

No desenvolvimento sócio histórico, os sujeitos transformam-se e transformam o meio através da apropriação da cultura. Assim, é a apropriação cultural que também define a forma de organização dos instrumentos e saberes compartilhados pelas e com as crianças. Este processo de apropriação cultural ocorre a partir das práticas desenvolvidas pelas gerações. As gerações mudam a história cultural do curso do desenvolvimento, sendo que as mais velhas, conforme Rogoff (2005), deixam um legado para os novos membros, em forma de instrumentos, tecnologias e saberes. Nos processos interativos com as crianças de 0 a 3 anos de idade, cada grupo cultural produz sentidos sobre o cuidado, encarnados na sua vida cotidiana, material e simbólica, contextualizando os instrumentos e os conhecimentos utilizados por cada família.

As competências dos bebês, assim, são vistas não a partir de marcadores biológicos, como meras restrições, limites ou potencialidades, mas desde sua interação com os aspectos culturais, a demandar olhares plurais para as diversas existências dos bebês concretamente situados. Contextualizar as práticas culturais de cuidado permite-nos compreender diferentes possibilidades de vivência deste período dos 0 aos 3 anos de idade e vencer o olhar que abstrai os sujeitos de seus espaços e normatiza padrões de desenvolvimento. Esta postura é defendida por Ruela e Moura (2007) que afirmam que, mesmo considerando um número crescente de pesquisas em diferentes culturas, a preferência é a investigação em contextos urbanos e industrializados, com tendência ainda de não reconhecimento das diversidades existentes nesses contextos. Em decorrência, as autoras afirmam que os conhecimentos resultantes das pesquisas produzem padrões sobre normalidade que são descontextualizados e, portanto questionáveis, com consequências para a orientação de programas de intervenção. A investigação dos diferentes ambientes de socialização seria, portanto, uma necessidade nos estudos de Psicologia do Desenvolvimento.

Seguindo esta lógica, a pesquisa estudou o cotidiano de um grupo de crianças e famílias no contexto de assentamento da reforma agrária. Destaca-se que o Brasil possui aproximadamente 977.039 famílias que vivem nas áreas de reforma agrária (INCRA, 2017), configurando uma particularidade nas formas de educação e cuidado das crianças de 0 a 3 anos de idade, filhas de assentados da reforma agrária.

\section{Construção do material empírico}

A pesquisa, realizada em um assentamento da reforma agrária, buscou evidenciar de que maneira o cuidado de crianças de 0 a 3 anos de idade estava atrelado à organização dos dias, das relações de suas famílias, suas atividades e seus espaços (ARAÚJO, 2013). Reconstruímos, por meio de uma investigação etnográfica em Psicologia (SATO; SOUZA, 2001; SCHMIDT, 2006), o dia a dia destas crianças e 
descrevemos algumas formas como eram significados e vivenciados seus cotidianos, seus lugares e seus mundos.

O assentamento situa-se na microrregião de Franca, no interior do Estado de São Paulo. O município em que a comunidade estava vinculada possuía população em torno de 7.000 habitantes, sendo 5.000 na região urbana e 2.000 na região rural.

A comunidade rural assentada, no momento da pesquisa, era constituída por 159 famílias, distribuídas em 2.979,07 hectares. O assentamento organizava-se em agrovilas e cada família assentada possuía um lote. Havia duas agrovilas distantes entre si aproximadamente $4 \mathrm{~km}$, e cada assentado possuía uma área na agrovila e um lote. Cada lote tinha em média 15 hectares. No assentamento, estavam presentes dois movimentos nacionais de luta pela terra, o Movimento dos Trabalhadores Sem-Terra MST e o Movimento de Libertação dos Sem Terra -MLST, organizados com forte influência do MST em uma agrovila e do MLST em outra.

Os recursos metodológicos utilizados na pesquisa foram: aplicação de questionário a 14 famílias com crianças de 0 a 3 anos (2 famílias possuíam 2 filhos com idade entre 0 a 3 anos, totalizando 16 crianças); observação durante 4 semanas acompanhando os dias de 3 crianças (Bárbara, 10 meses; Maria 1 ano e 5 meses; Joaquim, 2 anos e 5 meses) e suas famílias, registradas sob o formato de diário de campo; entrevistas áudio gravadas com as 3 famílias observadas. Neste momento, utilizaremos os dados obtidos por meio dos questionários para descrever o retrato do cuidado dos 16 bebês presentes na comunidade durante a realização da pesquisa.

\section{Articulações entre dias de bebês do campo e práticas de cuidado}

\section{O compartilhamento estendido}

A organização dos tempos e dos ambientes de cada criança, pelas pessoas do seu universo relacional, revelou uma prática comunitária do cuidado, na qual as necessidades e vontades dos bebês eram inseridas como parte das atividades coletivas de cada família.

O conjunto dos membros jovens e adultos das 14 famílias apresentou uma variação de 17 a 48 anos de idade. A média de filhos era 3 por família, superior à média nacional de 1,77 (IBGE,2014).

Sobre as crianças, todas nasceram na cidade próxima ao assentamento. Havia 9 crianças do sexo masculino e 7 do sexo feminino. No quadro a seguir, sintetizamos alguns indicadores que caracterizam as crianças investigadas, no interior da família:

Quadro 1. Distribuição das crianças em relação a alguns indicadores relativos à vida familiar

\begin{tabular}{c|c|c|c|c|c|c}
\hline BEBÊ & $\begin{array}{c}\text { IDADE } \\
\text { DA MÃE }\end{array}$ & $\begin{array}{c}\text { N }^{\circ} \\
\text { DE } \\
\text { FILHOS }\end{array}$ & $\begin{array}{c}\text { ORDEM DE } \\
\text { NASCIMENTO } \\
\text { DO BEBE }\end{array}$ & $\begin{array}{c}\text { MÃE } \\
\text { TRABALHA }\end{array}$ & $\begin{array}{c}\text { ONDE A } \\
\text { CRIANÇA FICA } \\
\text { DIARIAMENTE }\end{array}$ \\
\hline 1 & $\begin{array}{c}\text { Menina } \\
\text { de } 3\end{array}$ & 34 & 2 & $2^{\text {a filha }}$ & Sim & Própria casa \\
\hline
\end{tabular}




\begin{tabular}{|c|c|c|c|c|c|c|}
\hline & meses & & & & & \\
\hline 2 & $\begin{array}{l}\text { Menino } \\
\text { de } 2 \text { anos }\end{array}$ & 26 & 4 & $4^{\circ}$ filho & Sim & Própria casa \\
\hline 3 & $\begin{array}{l}\text { Menino } \\
\text { de } 3 \text { anos }\end{array}$ & 26 & 4 & $3^{\circ}$ filho & Sim & Própria casa \\
\hline 4 & $\begin{array}{l}\text { Menino } \\
\text { de } 1 \text { ano } \\
\text { e } 2 \text { meses }\end{array}$ & 24 & 2 & $2^{\circ}$ filho & Sim & Casa da Tia \\
\hline 5 & $\begin{array}{l}\text { Menino } \\
\text { de } 1 \text { ano } \\
\text { e } 5 \text { meses }\end{array}$ & 25 & 4 & $4^{\circ}$ filho & Sim & Própria casa \\
\hline 6 & $\begin{array}{l}\text { Menino } \\
\text { de } 3 \text { anos }\end{array}$ & 25 & 4 & $3^{\circ}$ filho & Sim & Própria casa \\
\hline 7 & $\begin{array}{c}\text { Menina } \\
\text { de } 7 \\
\text { meses }\end{array}$ & 27 & 4 & $4^{a}$ filha & Sim & Trabalho \\
\hline 8 & $\begin{array}{c}\text { Menino } \\
\text { de } 22 \text { dias }\end{array}$ & 17 & 1 & $1^{\circ}$ filho & Sim & Própria casa \\
\hline 9 & $\begin{array}{c}\text { Menina } \\
\text { de } 3 \text { anos }\end{array}$ & 44 & 8 & $7^{a}$ filha & Sim & Própria casa \\
\hline 10 & $\begin{array}{c}\text { Menina } \\
\text { de } 2 \text { anos }\end{array}$ & 26 & 2 & $2^{a}$ filha & Sim & Própria casa \\
\hline 11 & $\begin{array}{l}\text { Menina } \\
\text { de } 1 \text { ano } \\
\text { e } 11 \\
\text { meses }\end{array}$ & 35 & 4 & $4^{a}$ filha & Sim & Própria casa \\
\hline 12 & $\begin{array}{l}\text { Menina } \\
\text { de } 2 \text { anos }\end{array}$ & 28 & 2 & $2^{a}$ filha & Sim & Própria casa \\
\hline 13 & $\begin{array}{l}\text { Menino } \\
\text { de } 2 \text { anos }\end{array}$ & 19 & 2 & $2^{\circ}$ filho & Sim & Casa da Avó \\
\hline 14 & $\begin{array}{l}\text { Menino } \\
\text { de } 2 \text { anos }\end{array}$ & 20 & 1 & $1^{\circ}$ filho & Não & Própria casa \\
\hline 15 & $\begin{array}{c}\text { Menina } \\
\text { de } 10 \\
\text { meses }\end{array}$ & 48 & 6 & $\begin{array}{c}5^{\text {a }} \text { filha (era } \\
\text { afilhada, mas } \\
\text { cuidada no interior } \\
\text { da família como } \\
\text { filha) }\end{array}$ & Sim & Própria casa \\
\hline 16 & $\begin{array}{l}\text { Menina } \\
\text { de } 1 \text { ano } \\
\text { e } 4 \text { meses }\end{array}$ & 25 & 1 & $1^{\text {a }}$ filha & Sim & Casa da Avó \\
\hline
\end{tabular}

Fonte: Araújo, 2013

As crianças pesquisadas passavam os dias, majoritariamente, nas próprias casas, sendo que 3 delas ficavam na casa da avó ou da tia e uma acompanhava a mãe no trabalho. Os trabalhos realizados pelas mães eram de diarista, doméstica, administradora de empresa, presidente de uma associação de produtores e agricultora. Estar na casa, contudo, não restringia o convívio da criança aos cuidadores principais. Das 
14 mulheres entrevistadas, que se colocaram como responsáveis pelo cuidado e pela educação das 16 crianças de 0 a 3 anos, somente 4 delas declararam exclusividade no cuidado de seu filho, justificado, principalmente, pelo fato de não trabalharem fora da casa e do lote. Já 10 delas evidenciavam a partilha desta responsabilidade com os avós, os tios, os irmãos, os sobrinhos e os vizinhos.

A corresponsabilidade do cuidado e da educação das 16 crianças acontecia, em 12 casos, não apenas entre as mães e os membros familiares (pai, avó, irmãos, tia materna, sobrinhas maternas), mas também com amigos, durante a realização do trabalho doméstico e agrário da mãe no assentamento.

\section{Relações, atividades e espaços dinâmicos}

A interatividade comunitária pode ser percebida pelas redes de relações de cada criança:

Quadro 2. Redes de relações de cada criança de acordo com local de moradia e com a geração de parceiros

\begin{tabular}{|c|c|c|c|c|c|c|}
\hline \multirow{2}{*}{$\begin{array}{l}\text { Criança } \\
\qquad \text { Idade }\end{array}$} & \multirow{2}{*}{ Mãe } & \multirow{2}{*}{$\begin{array}{c}\text { Local de } \\
\text { moradia no } \\
\text { assentamento }\end{array}$} & \multicolumn{4}{|c|}{ Parceiros de interação cotidiana } \\
\hline & & & Adultos & Jovens & Crianças & TOTAL \\
\hline Menina de 3 meses & Karina & Agrovila & 2 & 0 & 1 & 3 \\
\hline Menino de 2 anos & Débora & Lote & 1 & 1 & 3 & 5 \\
\hline Menino de 3 anos & Débora & Lote & 1 & 1 & 3 & 5 \\
\hline $\begin{array}{c}\text { Menino de } 1 \text { ano e } 2 \\
\text { meses }\end{array}$ & Pamela & Agrovila & 3 & 0 & 1 & 4 \\
\hline $\begin{array}{c}\text { Menino de } 1 \text { ano e } 5 \\
\text { meses }\end{array}$ & Sofia & Agrovila & 8 & 4 & 2 & 14 \\
\hline Menino de 3 anos & Sofia & Agrovila & 8 & 4 & 2 & 14 \\
\hline Menina de 7 meses & Maiara & Lote & 1 & 0 & 3 & 4 \\
\hline Menino de 22 dias & Anamaria & Agrovila & 8 & 4 & 4 & 16 \\
\hline Menina de 3 anos & Mariana & Lote & 2 & 5 & 2 & 9 \\
\hline Menina de 2 anos & Teresa & Lote & 2 & 0 & 3 & 5 \\
\hline $\begin{array}{c}\text { Menina de } 1 \text { ano e } 11 \\
\text { meses }\end{array}$ & Leticia & Agrovila & 2 & 2 & 1 & 5 \\
\hline Menina de 2 anos & Helen & Agrovila & 5 & 1 & 1 & 7 \\
\hline Menino de 2 anos & Isabella & Lote & 2 & 0 & 3 & 5 \\
\hline Menino de 2 anos & Joaquina & Agrovila & 3 & 0 & 1 & 4 \\
\hline Menina de 10 meses & Paula & Agrovila & 8 & 4 & 4 & 16 \\
\hline $\begin{array}{c}\text { Menina de } 1 \text { ano e } 4 \\
\text { meses }\end{array}$ & Cristina & Lote & 10 & 1 & 3 & 14 \\
\hline \multicolumn{3}{|c|}{ TOTAL } & 49 & 18 & 28 & 95 \\
\hline
\end{tabular}

Fonte: Araújo, 2013 
São 49 adultos, 18 jovens e 28 crianças que, além de serem interlocutores, tornavam-se também meios e recursos no processo de desenvolvimento das 16 crianças de 0 a 3 anos (Wallon, in Werebe\&Nadel, 1986). Eram vários os papéis exercidos pelos adultos (pais, mães, tios, avôs, avós, madrinhas, padrinhos, irmãos e irmãs, mães e avós postiços). Outros papéis também eram desempenhados pelos adultos, por outras crianças e por jovens: agricultores, estudantes, vizinhos, diaristas, carvoeiros, militantes, cooperados, associados, entre outros. Seus diferentes papéis os qualificavam como pertencentes a grupos e, na relação com as crianças, possibilitavam contra papéis a partir desses outros categoriais (WALLON, 1986).

A forma de participação destas pessoas no cuidado das crianças, em momentos específicos do dia, revelou a forte presença das mulheres.

Figura 1. Pessoas participantes como cuidadoras das crianças, em momentos específicos do dia.

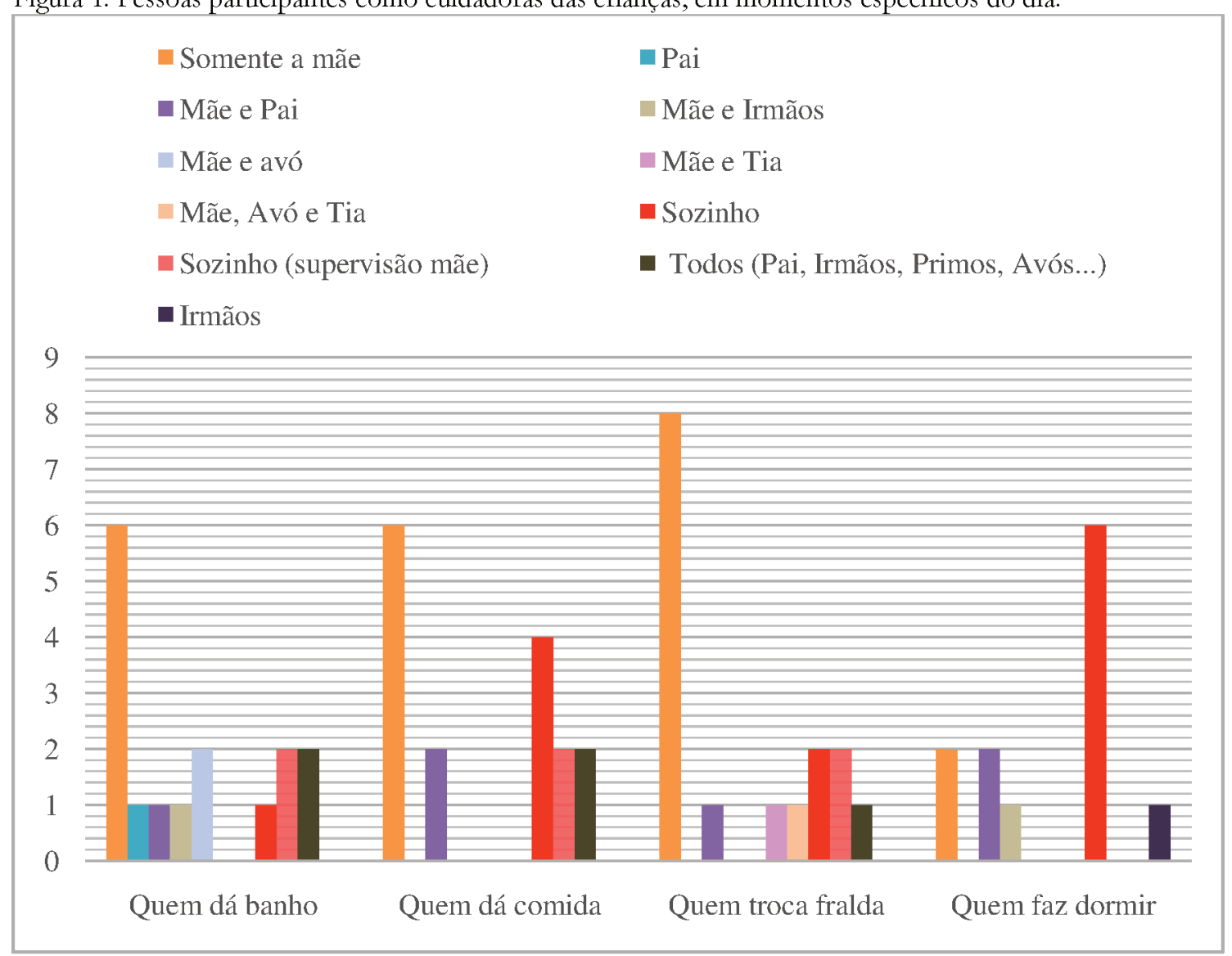

Fonte: Araúio, 2013

Em relação aos responsáveis pelo banho, além dos 6 nos quais a mãe disse ser a única responsável, 10 casos contavam com outros cuidadores: avós, irmãos, pais, tias, além de tomarem banho sozinhos ou sob a supervisão das mães. 
Em relação à alimentação, somente as mães eram responsáveis em 6 casos, 2 relataram que a atividade era realizada com o pai e a mãe juntos, 4 que a criança comia sozinha, 2 que as refeições eram feitas sob a supervisão da mãe, 2 com a ajuda de todos os familiares.

Das 16 crianças de 0 a 3 anos, 7 ficavam exclusivamente com as mães, seja na casa, no lote ou na casa da patroa (no caso das diaristas domésticas), sendo 4 destas as que levavam suas crianças para o seu trabalho fora da casa. Em relação às outras 9 crianças, elas contavam cotidianamente com o apoio de familiares e amigos em seu cuidado e em sua educação.

Figura 2. Com quem e onde as crianças dormem.

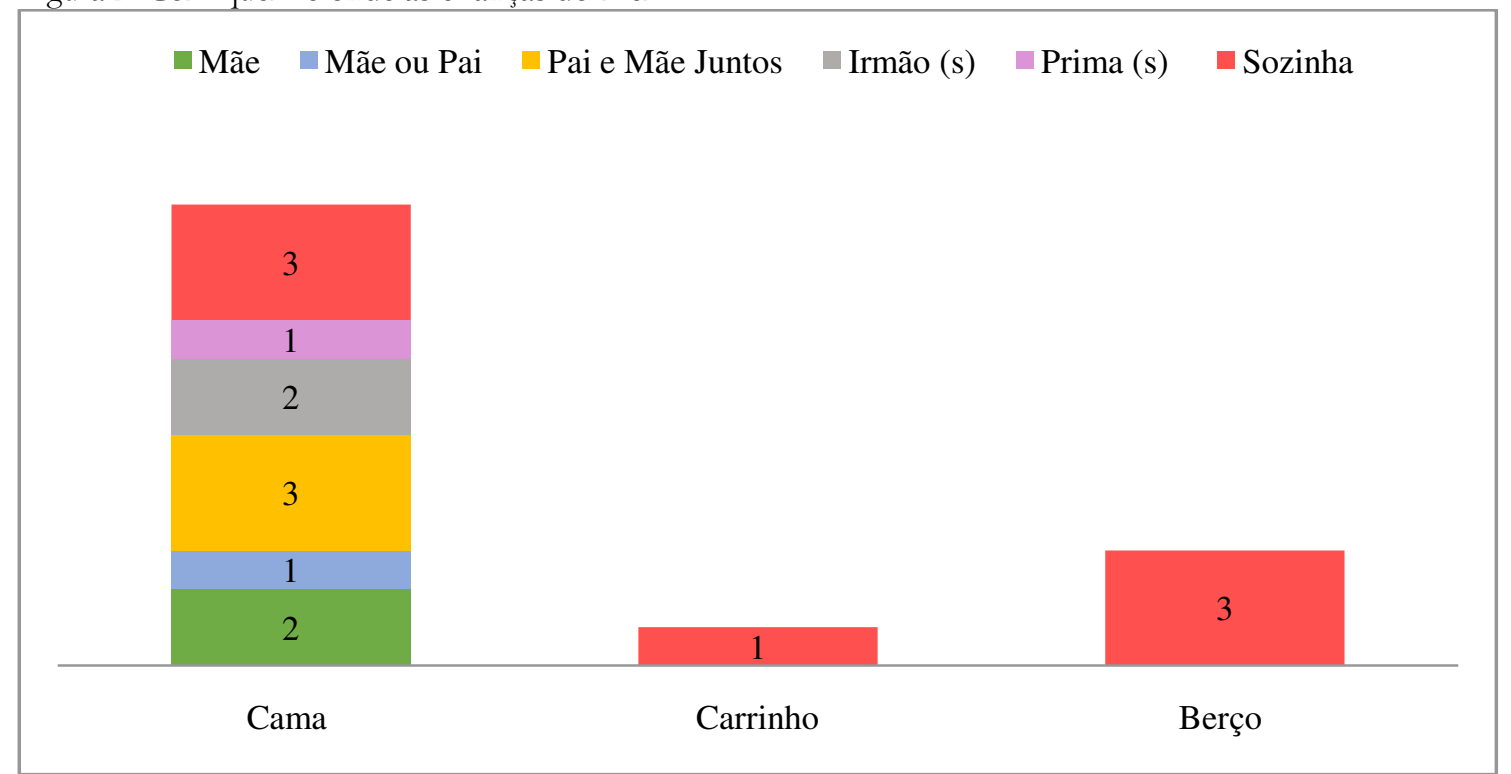

Fonte: Araújo, 2013

A informação sobre o local onde dormiam evidenciou uma relação de muita proximidade e compartilhamento do espaço com outros membros da família: 9 crianças dormiam em cama, junto com as mães, as mães e os pais, os irmãos ou prima; outras 7 dormiam em cama sozinhas (3), em berço (3) ou em carrinho (1).

Sobre a relação dos participantes com outras crianças da comunidade, 6 conviviam com crianças da sua idade. As outras 10 conviviam com crianças mais velhas entre a faixa etária de 1 ano e 5 meses a 6 anos.

Em relação aos arranjos espaciais, como parte da rotina familiar, as crianças vivenciavam, além do espaço da própria casa: o lote; a igreja; a horta; o galinheiro; o chiqueiro; a escola do assentamento; as cidades da região; o centro cultural do movimento; casas de parentes. As crianças de 0 a 3 anos atuavam concretamente de forma integrada às escolhas de espaços ocupados e atividades realizadas pelos seus familiares. Os espaços experenciados pelos familiares cruzavam-se com os disponibilizados e escolhidos para e pelas crianças. 
As atividades inerentes aos espaços organizavam-se a partir das dinâmicas que se davam nas vivências da produção econômica da vida dos assentados, na produção, consumo e venda dos produtos pelas cooperativas.

Figura 3. Atividades que as crianças realizam em seu dia a dia.

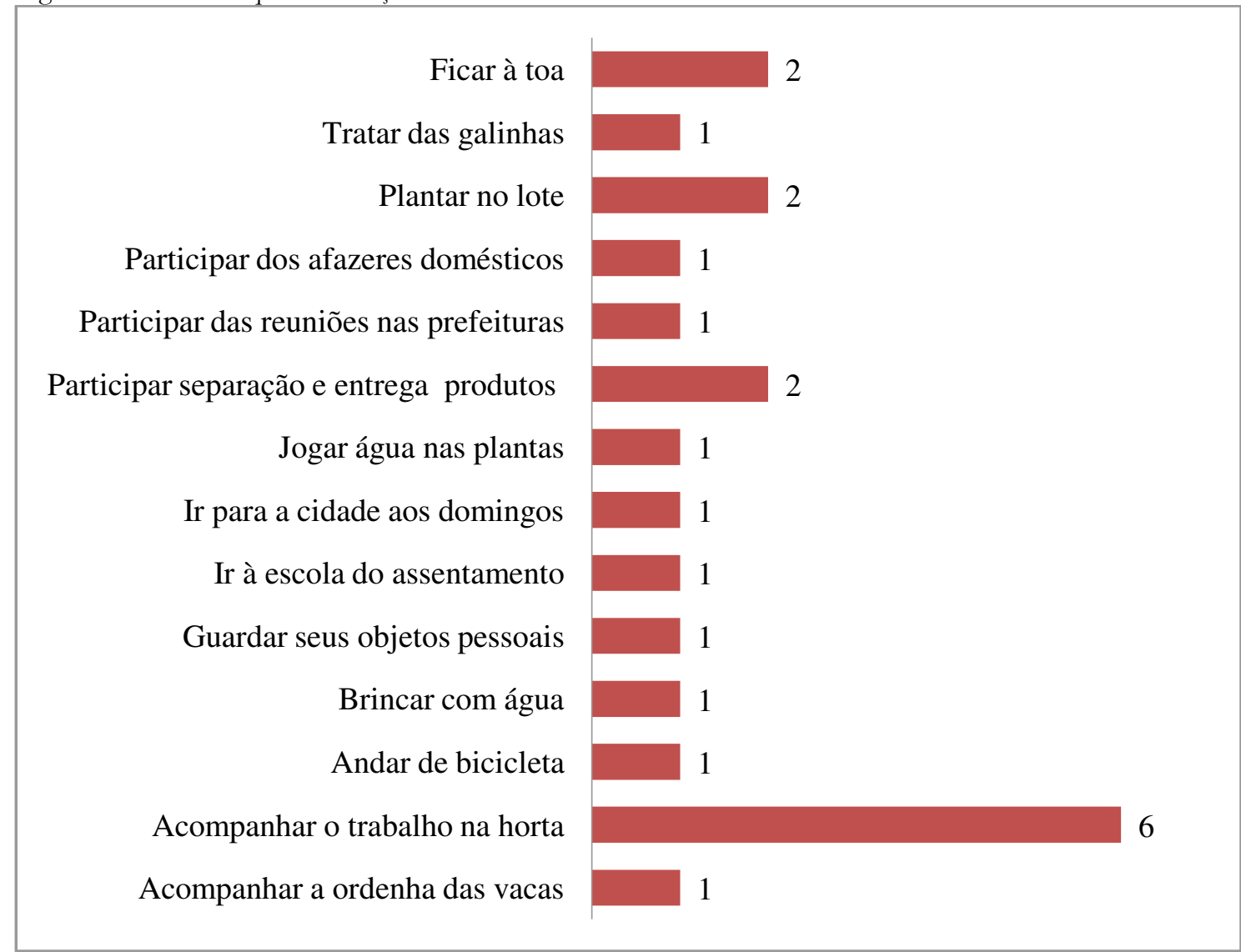

Fonte: Araújo, 2013

A partir das atividades e dos espaços possibilitados, percebe-se certa mobilidade das crianças. Chama a atenção o fato de apenas 2 das mães terem respondido, como uma das atividades, que a criança brincava (brincar com água; andar de bicicleta). Nos outros casos, as atividades descritas acompanhavam as atividades realizadas também por adultos. Entre estas, 6 disseram, de modo genérico, que as crianças acompanhavam o trabalho na casa e na horta.

As mulheres responsáveis pelas crianças elencaram um rol de brincadeiras de seus filhos e de suas filhas de 0 a 3 anos. Os cenários onde ocorriam estas brincadeiras eram os espaços nos quais as atividades descritas anteriormente se desenvolviam. 
Figura 4. Com quem e de quê as crianças brincam.

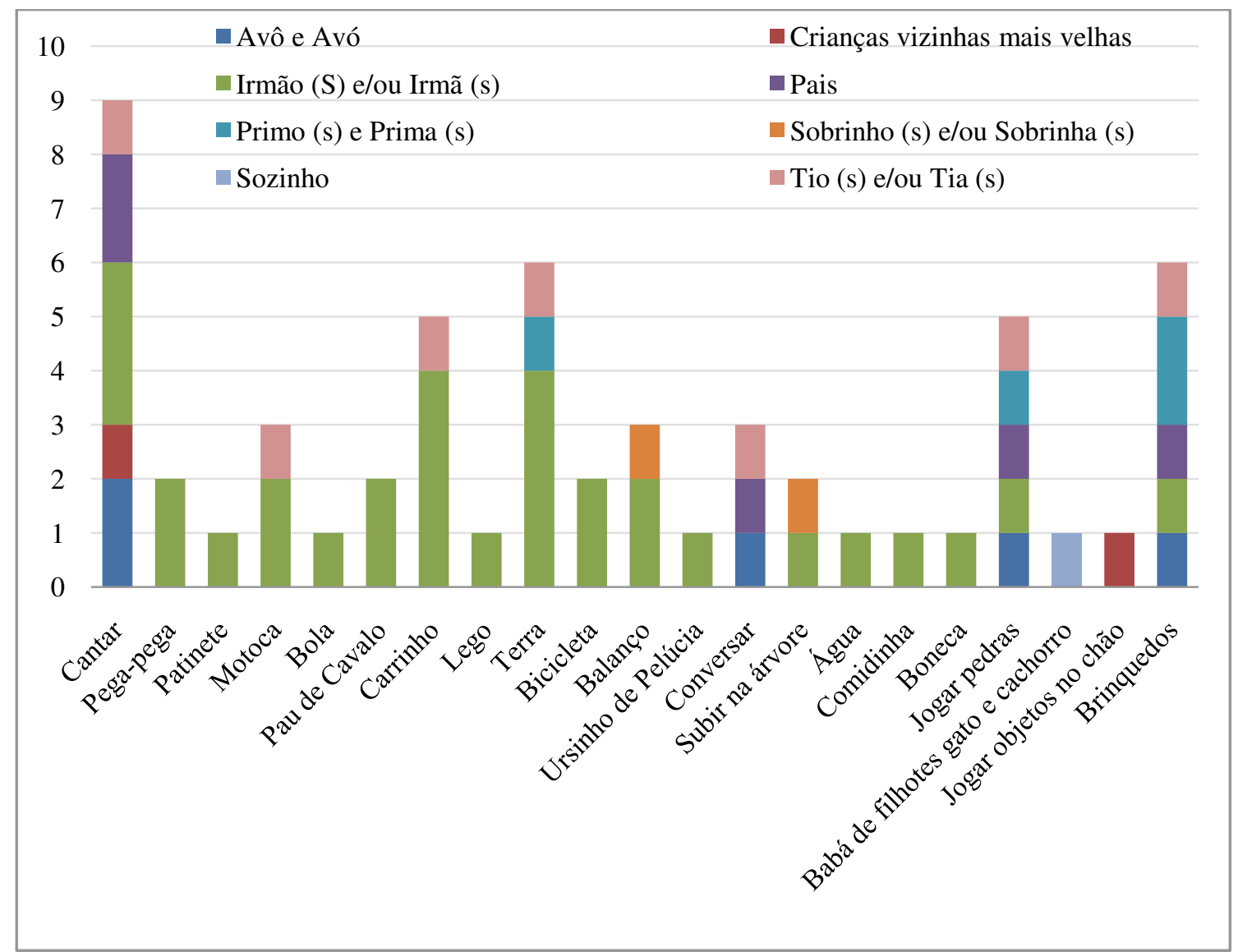

Fonte: Araújo, 2013

Sobre as informações da Figura 4, são marcantes a participação dos irmãos e/ou irmãs e a diminuída participação dos pais nas atividades de brincadeira. No entanto, o gráfico revela que havia uma participação direta de outros membros familiares, bem como vizinhos. Esta diversidade revela aspectos relativos às maneiras pelas quais as atividades, os espaços e os tempos eram apropriados, como possibilidades de brincadeira, pelas crianças.

A dinâmica da vida produtiva, associada à ausência de um espaço institucional para as crianças até 3 anos, no assentamento, gerava uma situação em que os dias das crianças encontravam-se extremamente vinculados às atividades das famílias, principalmente, das mulheres. Neste processo, também o conceito "doméstico" era ressignificado, sendo a ele incorporado o espaço dos quintais, a plantação e os lotes, expandindo os espaços geralmente identificados como seguros para a mobilidade assistida ou autônoma da criança. 
Quadro 3. Espaços de mobilidade da criança, ao longo de uma semana

\begin{tabular}{|c|c|c|c|}
\hline Idade Gênero & 0 a 1 ano & 1 a 2 anos & 2 a 3 anos \\
\hline \multirow{5}{*}{ FEMININO } & $\begin{array}{c}\text { Na casa da avó e da tia } \\
\text { na cidade }\end{array}$ & $\begin{array}{l}\text { Quintal da área da } \\
\text { agrovila }\end{array}$ & Galinheiro \\
\hline & \multirow[b]{2}{*}{ Horta } & Igreja & Entorno da casa do lote \\
\hline & & Lote & Cooperativa \\
\hline & \multirow{2}{*}{ Casa } & Entorno da casa no lote & \multirow{2}{*}{ Lote } \\
\hline & & Casa do Pai na cidade & \\
\hline \multirow{8}{*}{ Masculino } & \multirow{2}{*}{ Casa } & Casa da Tia na agrovila & $\begin{array}{l}\text { Casa de vizinhos da } \\
\text { comunidade }\end{array}$ \\
\hline & & $\begin{array}{c}\text { Escola do } \\
\text { Assentamento }\end{array}$ & Casa da avó na cidade \\
\hline & \multirow{3}{*}{$\begin{array}{l}\text { Casa da avó no } \\
\text { assentamento }\end{array}$} & \multirow[t]{2}{*}{ Quintal } & Casa \\
\hline & & & Cidade \\
\hline & & \multirow[t]{2}{*}{ Represa } & $\begin{array}{c}\text { Entorno da casa da } \\
\text { agrovila }\end{array}$ \\
\hline & \multirow{3}{*}{ Escritório da associação } & & Entorno da casa no lote \\
\hline & & \multirow[t]{2}{*}{ Rua da agrovila } & $\begin{array}{l}\text { Entorno da casa do } \\
\text { Lote }\end{array}$ \\
\hline & & & Represa \\
\hline
\end{tabular}

Fonte: Araújo, 2013

A mobilidade das crianças acontecia, em grande parte, com e pelas suas mães. Um bebê de 7 meses era levado à horta em seu carrinho; um recém-nascido de 22 dias acompanhava sua mãe no escritório de seu trabalho, localizado em um espaço da própria área da agrovila. A maior mobilidade acontecia no caso de uma bebê de 10 meses, que circulava em todos os espaços de atuação de sua madrinha (considerada como mãe), o que incluía atividades na agricultura, na Associação de mulheres e na liderança e militância do movimento social.

\section{Significações sobre o cuidado e a educação da criança}

As atividades, os espaços e as brincadeiras possibilitados às 16 crianças estavam circunscritos a uma rede de interações e significados sobre o cuidado e a educação das crianças de 0 a 3 anos do campo. Chamou atenção o fato de que, ao construírem estas significações, as participantes trouxeram, para a conversa com a pesquisadora, uma comparação entre o campo e a cidade, apontando as diferenças no cuidado e na educação das crianças.

Das 14 mulheres entrevistadas, somente 1 não discriminava o cuidado e a educação no campo ou na cidade. As outras 13 apresentam significações gerais a todas as crianças e algumas específicas para as crianças do campo. Sobre as compreensões gerais, as responsáveis pelas crianças acreditavam ser importante:

Respeito ao próximo. A educação é obrigação, tanto com as pessoas aqui de dentro quanto com as de fora. A gente vai longe com educação e respeito. (Teresa, mãe de menina de 2 anos e 8 meses). 
É crescer humilde, tem que estudar, ser compreensivo. Ajudar qualquer pessoa. Eu gosto de estudar, ele vai também. (Anamaria, mãe de menino de 23 dias).

As significações eram perpassadas pelos sentidos sobre seus comportamentos adequados, suas necessidades e suas vontades. Estes diferenciavam-se pelo próprio sentido de viver no campo e o que ele proporcionava no cuidado e na educação de seus filhos:

Eu acho melhor do que na cidade, é mais saudável, come verdura, fruta, a alimentação, não tem poluição. Meu filho que mora na cidade só come bolacha. (Karina, mãe de menina de 3 meses).

Roça tem mais saúde. Assiste TV, fica no quintal. É livre. As crianças da cidade não ficavam na rua. (Sofia, mãe de dois meninos de 1 ano e 5 meses, e 3 anos e 3 meses).

Crianças têm mais saúde no campo. Na cidade, as crianças ficam muito doentes. (Maiara, mãe de menina de 7 meses).

Quase não fica doente. (Letícia, mãe de menina de 1 ano e 11 meses).

A vida no campo foi significada como uma possibilidade dos bebês se desenvolverem ao terem contato com a terra, com a natureza e com os animais, configurando uma vida mais saudável. Ainda, a participação da família no dia a dia era organizada de forma a possibilitar à criança aprendizados, considerando o campo como um contexto específico de desenvolvimento.

Procura voltar mais para o campo. Ensinar ele a amar mais o campo, cuidar dos lixos, dos animais... Se jogar tem que catar. Cultivar isso neles para que quando eles crescerem, não vão para a cidade. (Débora, mãe de dois meninos um de 2 anos e outro de 3 anos).

Valorizar o campo por estar aqui. (Débora, mãe de dois meninos um de 2 anos e outro de 3 anos).

Ele saber respeitar uma plantinha. A criança pega gosto por isso aqui. Ele aprende a cuidar de uma planta. (Teresa, mãe de menina de 2 anos e 8 meses).

Brincar, porque na hora que brinca é que desenvolve. Não adianta prender, tem que ir pra terra. (Pamela, mãe de menino de 1 ano e 2 meses).

Para as participantes, tendo seu cuidado e sua educação atrelados a esses elementos específicos do campo, a criança poderá futuramente valorizá-lo, assim como reconhecer a luta de seus pais pela terra.

A criança do campo vai saber se virar aqui no campo. Eu quero que ele cresça sem menosprezar as crianças da cidade. Ele vai ter liberdade de participar das coisas. (...).Eu prefiro que ele viva aqui, ele vai crescer com todo mundo, falando Oi para todo mundo, andar a cavalo. (Anamaria, mãe de menino de 23 dias).

É a fase mais importante da criança aprender a gostar do campo, porque senão, cresce e vai para a cidade, e acaba que a gente brigou [pela terra] à toa. (Paula, madrinha de menina de 10 meses).

No cuidado, o campo requer cuidado com os bichos. Na educação, agora é fase dela aprender a brincar. A criança é menos fresca. Na roça, vai lidando com a terra, 
entendendo que é instrumento de trabalho. A criança é mais resistente. (Cristina, mãe de menina de 1 ano e 4 meses).

A liberdade proporcionada pela vida no campo também merece seus cuidados diante da tranquilidade que este apresenta.

Viso muito a segurança, questão de bichos, cobra, o que come. Ao mesmo tempo que aparenta ser um lugar tranquilo, tem seus perigos. (Helen, mãe de menino de 2 anos).

Tomar cuidado para não machucar, perigoso bicho por causa da roça. (Isabella, mãe de menino de 2 anos).

Resumidamente, o material construído na pesquisa nos permite dizer que os dias dos bebês do campo foram definidos pelos tempos, espaços e atividades de suas famílias concretas, assentadas da reforma agrária, organizadas em cooperativas e associações, e distribuídas espacialmente em lotes e agrovilas. Suas atividades, necessidades e vontades foram integradas às atividades e necessidades diárias de cada família: no cuidado das plantações e dos animais de sua propriedade; na realização de pequenos serviços como carvoeiros e diaristas domésticas; na produção de quitandas; na organização cooperativa entre os assentados; na produção e comercialização dos alimentos. Sendo assim, os dias das crianças pequenas foram organizados e perpassados pela escolha coletiva do que e como plantar e pelo processo de cuidar do que plantou e como vender. $\mathrm{Na}$ construção destes dias, família e comunidade interagiram no cuidado de seus pequenos.

\section{Considerações finais}

Imersos em rede de relações extensas, os bebês da comunidade investigada têm seus cuidados e sua educação organizados diariamente conforme as concepções e as expectativas de seus responsáveis, familiares ou não. De modo geral, as significações sobre o cuidado e educação das crianças pequenas revelam que os bebês do campo foram concebidos como sujeitos sociais e políticos, nas práticas de cuidado nas experiências sociais e históricas de cada membro da família, da comunidade e do contexto rural.

Em geral, a decisão do que, como, com quem e onde compartilhar o cuidado é tomada pelas mulheres, consideradas por elas mesmas as responsáveis principais pelas crianças e pela casa. Elas são e colocam-se como responsáveis por definir: a rotina; as atividades domésticas; a alimentação das crianças; os lugares onde vão, como e com quem. São definições e orientações realizadas diariamente que compõem os diferentes papéis que estas mulheres ocupam como mães, militantes, quitandeiras, diaristas, carvoeiras e também madrinhas e avós. Há, entretanto, um diálogo entre o que necessitam em seus cuidados diários e as atividades domésticas e de trabalho, da família e da comunidade.

Cada família precisa, assim, desenvolver estratégias de cuidado de seus filhos pequenos, compartilhando-o entre seus membros, de diferentes idades. São nos movimentos de seus parceiros de interação em seus dias de trabalho, seja no lote, na cidade ou no ambiente doméstico, que os bebês 
reconhecem e são reconhecidos em seus espaços, seus lugares e seus cotidianos. Evidencia-se, portanto, uma verdadeira mobilização de todos os membros das famílias e conhecidos como forma de conciliar as atividades da família e as necessidades das crianças. Irmãos assumem responsabilidades, avós assumem-se como mães, os pais também colaboram.

A configuração destas redes de relações redefine o entendimento de família. Como primeiro grupo social do bebê, é compreendida, conforme Fonseca (2005), não como uma unidade, mas como um complexo de dinâmicas e relações decorrentes de diferentes arranjos possíveis. Este entendimento e a configuração encontrada na comunidade nos ajudam a pensar que a organização da família implica em situar suas práticas cotidianas em relação não só aos seus membros consanguíneos, mas também a membros por laços de criação. A extensão da família depende assim do compartilhamento das práticas cotidianas das pessoas que convivem no contexto familiar.

Nesse sentido, não há uma receita que defina os membros relevantes de uma rede familiar. Segundo Fonseca (2005, p.53),

Essa pode ou não incluir consanguíneos (ascendentes, descendentes, colaterais etc.), parentes por casamento (sogros, cunhados, concunhados, padrastos, enteados etc.), padrinhos e compadres (não devemos esquecer que existem padrinhos em casa, de igreja, na Família de santo, etc.), e simplesmente amigos que, depois de ter compartilhado uma experiência particularmente intensa, acabam se sentindo membro da Família.

Uma rede de relações provoca o compartilhamento do cuidado das gerações mais novas entre os diferentes membros da família extensa (AMORIM; VITORIA; ROSSETTI-FERREIRA, 2000). Os familiares organizam seus ambientes conforme suas concepções e expectativas sobre o desenvolvimento daquela criança e sobre seu próprio papel em relação a ela, adquiridas através de experiências situadas na cultura.

Partindo de uma abordagem que evidencia as interações humanas como constitutivas do desenvolvimento humano (CARVALHO; PEDROSA; ROSSETTI-FERREIRA, 2012), as redes de relações da família extensa apresentam um mundo cheio de pessoas, atividades e espaços que convivem com as crianças até 3 anos no assentamento, o que caracteriza uma vida social bastante intensa.

A diversidade de atividades e espaços conformam um conjunto de cenários e uma ambiência que circunscreviam e mobilizavam as significações produzidas pela comunidade, favorecendo e mediando, à criança, o domínio dos modos de pensar, sentir e agir do seu grupo. Nos tempos e espaços que perpassavam a configuração destas atividades, os bebês eram considerados como daquele ambiente.

A concepção no senso comum, de fragilidade do bebê, é problematizada a partir do material de pesquisa. Embora tenha sido constante a preocupação dos assentados em relação aos cuidados que a faixa etária exigia, a inserção dos bebês nas atividades desenvolvidas pelos adultos era corriqueira. Esta prática inseria a criança na vida produtiva da família e permitia ampla circulação e exploração de espaços diferenciados, próprios da conformação socioambiental de um assentamento de reforma agrária. 
A aproximação aos dias das crianças de 0 a 3 anos em assentamento rural, de seus familiares e de sua comunidade, revelou-nos ainda uma variedade de arranjos, combinações e modos de cuidado e de educação. Foram identificados vários cenários de desenvolvimento, espaços compostos por diversos elementos do/no campo, atividades relacionadas às características dos espaços, com diferentes recursos de interação e ação das pessoas que os compõem.

Numa perspectiva que considera os bebês do campo como sujeitos singulares, imersos em redes de relações e significações constitutivas de um ambiente marcado pelas formas de garantir a sobrevivência das famílias, verificamos que os sujeitos estabelecem práticas cotidianas de cuidado, numa disposição de estar com os bebês do campo, na concretude de suas relações, atividades, tempos e espaços, fortemente integrados aos dos adultos. Este entendimento nos ajuda a pensar quão ricas são as oportunidades dos bebês de se apropriarem da cultura dos adultos e se tornarem capazes de se relacionar com os espaços, tempos e atividades do campo.

O modo de vida no campo é perpassado por uma rede de solidariedade forte, criada entre os membros de diferentes gerações da família para o cuidado da criança pequena. Restaria a indagação se essas redes não estariam sendo criadas em virtude apenas da necessidade, dada a ausência de políticas públicas para a criança do campo. O material permite dizer que não é apenas isso. As relações afetivas, carinhosas, de manifesta retribuição de favores e de compadrio marcam processos psicossociais que, embora construídos a partir das condições e necessidades concretas das famílias, a elas não se restringem ou se reduzem. Outra indagação a respeito deste fato, que merece ser aprofundada, seria ainda se esta situação refletiria uma compreensão de bebês e de comunidade como agentes ativos no desenvolvimento. De toda a forma, pode-se pensar que a ausência de política pública para a infância até 3 anos, no campo, joga um papel central nos modos como a família organiza-se em relação ao acesso aos direitos das crianças

Cabe também mencionar que compreender o cuidado do bebê do campo implica considerar o entendimento da comunidade sobre os seus bebês. Nesse exercício, haveria que fazer dialogar as questões que são gerais do cuidado privado ao ambiente doméstico e as especificidades das vivências das crianças, em diferentes comunidades rurais.

Por fim, é necessário dizer que o cuidado dos bebês do campo, em seu cotidiano, a partir das relações estabelecidas em comunidade, pode também ajudar-nos a entender a riqueza das trocas entre os membros da comunidade para o desenvolvimento. Distanciando-nos de uma perspectiva que idealiza o campo como espaço único, foi possível conhecer que a própria comunidade rural considera seus bebês, suas famílias e seus pares em suas necessidades etárias e de cuidado. 


\section{Referências}

ARAÚJO, Marcella Oliveira. O cotidiano das crianças de 0 a 3 anos de idade de uma comunidade rural: significações e práticas familiares. Dissertação (Mestrado em Psicologia). Faculdade de Filosofia, Ciências e Letras de Ribeirão Preto, Universidade de São Paulo, 2013.

CARVALHO, Ana Maria Almeida; PEDROSA, Maria Isabel; ROSSETTI-FERREIRA, Maria Clotilde. Aprendendo com a criança de 0 a 6 anos. São Paulo: Editora Cortez, 2012.

FIDALGO, Zilda. Psicologia Cultural e Desenvolvimento Humano: Um encontro com Barbara Rogoff. Análise Psicológica, Lisboa, v. 22, n. 1, 7-9, 2004.

FONSECA, Claudia. Concepções de família e práticas de intervenção: uma contribuição antropológica. Saúde e Sociedade, v. 14, n. 2, 50-59, 2005.

IBGE.Instituto Brasileiro de Geografia e Estatística. Resultados Gerais da Amostra Censo Demográfico 2010. Brasília, 2012.

INCRA. Instituto Nacional de Colonização e Reforma Agrária. Dados de caracterização. Brasília, 2017. Disponível em: www.incra.gov.br

PINO, Angel. As marcas do humano: as origens da constituição cultural da criança na perspectiva de Lev. S. Vigotski. São Paulo: Cortez, 2005.

ROGOFF, Barbara. Cognition as a collaborative process. In: DAMON, Willian; LERNER, Richard M.; KUHN, Deanna \&SIEGLER, Robert S. (Orgs.). Handbook of child psychology: cognition, perception and language, 679-744. New York: Wiley, 1998, pp. 679-744.

ROGOFF, Barbara. A natureza cultural do desenvolvimento humano. Tradução Roberto Cataldo Costa. Porto Alegre: Ed. Artes Médicas, 2005.

ROSSETTI-FERREIRA, Maria Clotilde. Olhando a pessoas e seus outros, de perto e de longe, no antes, aqui e depois. In: COLINVAUX, Dominique; BANKS-LEITE, Lucy \& DELL'AGLIO, Débora Dalbosco. Psicologia do desenvolvimento: reflexões e práticas atuais. São Paulo: Casa do Psicólogo, 2006, pp. 19-62.

SATO, Leny; SOUZA, Marilene Proença Rebello. Contribuindo para desvendar a complexidade do cotidiano através da pesquisa etnográfica em Psicologia. Psicologia USP, São Paulo, v. 12, n. 2, 29-47, 2001.

SCHMIDT, Maria Luisa Sandoval. Pesquisa participante; alteridade e comunidades interpretativas. Psicologia USP, São Paulo, v. 17, n.2, 11-41, 2006.

RUELA, Sanya Franco; MOURA, Maria Lucia Seidl de. Um estudo do nicho de desenvolvimento de um grupo de crianças em uma comunidade rural. Psicologia em estudo, Maringá, v. 12, n. 2, 315-324, 2007.

VIGOTSKI, LevSemenovitch. Obras escogidas. Psicología Infantil. Vol. 4. Madrid: Antonio Machado Libros, 2006.

WALLON, Henri. Os meios, os grupos e a psicogênese da criança. In: WEREBE, M.J.G. NADELBRUlfERT, J. (Orgs.). Henri Wallon. Tradução de Elvira Souza Lima, São Paulo: Ática, p. 168-178, 1986. 
Recebido em: 31/03/2016 Aprovado em: 01/05/2016 